\title{
Nomear as coisas: sobre algumas inscrições pintadas na cerâmica ática arcaica
}

\author{
François Lissarrague ${ }^{[]]}$
}

\begin{abstract}
Resumo
Este artigo estuda a maneira pela qual os pintores de vasos às vezes associaram aos objetos representados inscrições que os nomeiam. Não se trata de explicar a imagem, mas de atrair o olhar sobre os elementos da representação, que têm uma importância narrativa ou simbólica forte.

Palavras-chave: Cerâmica grega, inscrições, narrativa.

\section{Nombrar las cosas: sobre algunas inscripciones pintadas en la cerámica ática arcáica}

\section{Resumen}

Este artículo estudia la forma que los pintores de jarrones a veces asociaron a los objetos representados inscripciones que los nombran. No es para explicar la imagen, pero de echar la mirada sobre los elementos de la representación que tienen una importancia narrativa o simbólica fuerte.

Palabras-clave: Cerámica griega; inscripciones; narrativa.

\section{Naming things: about some inscriptions in archaic attic ceramics}

\begin{abstract}
This paper concentrates on the way vase painters have sometimes associated with objects depicted inscriptions naming these objects. By doing so they do not intend to explain the picture, but to catch the eye and draw attention on elements which have a strong narrative or symbolic value.

Keywords: Greek vase-painting; inscriptions; narration.

\section{Nommer les Choses: à propos de quelques inscriptions peintes dans la céramique attique archaïque}

\section{Résumé}

Cet article étudie la façon dont les peintres de vases ont parfois associé aux objets représentés des inscriptions qui les nomment. Il ne s'agit pas, ce faisant, d'expliquer l'image mais d'attirer le regard sur des éléments de la représentation qui ont une importance narrative ou symbolique forte.

Mots-clés: Céramique grecque; inscriptions; narration. 
$\mathrm{P}$ ara quem procura conhecer melhor o papel da escrita no início da Grécia antiga, entre oralidade e memória coletiva, as inscrições pintadas nos vasos são de maior interesse, tanto por sua variedade quanto por sua quantidade. ${ }^{2}$ As mais antigas inscrições pintadas são as assinaturas dos oleiros, que se destacavam em um duplo domínio: o das artes do fogo e o da própria escrita. Essas são, a partir do fim da fase geométrica, as inscrições definidas, cuidadosamente guiadas pelo sistema ornamental, que organizam a superfície do vaso, cujo papel é tanto linguístico - por apresentar o nome do oleiro quanto pictórico - pois fazem parte da decoração do vaso. Desde as primeiras inscrições, o duplo sentido de graphein - escrever e desenhar - é assim assumido pelos oleiros que assinam. Este é o caso do fragmento de cratera encontrado em Ischia, tal como uma oenochoé geométrica de Ítaca. ${ }^{3}$

Ao lado dessas assinaturas, a partir das gerações seguintes, encontramos uma grande variedade de inscrições: muitas dão nome aos personagens, hérois ou deuses, em particular nas cenas mitológicas, como Nesso ou Héracles na ânfora de Elêusis. ${ }^{4}$ A grande cratera assinada (duas vezes) pelo pintor Kleitias e pelo oleiro Ergotimos marca o apogeu do uso das inscrições. ${ }^{5}$ Outro exemplo dessa dupla assinatura, o vaso contém 130 inscrições que dão nome, não somente aos deuses do cortejo que visita Peleu, ou aqueles que assistem ao retorno de Hefesto ao Olimpo, mas também aos centauros que lutam contra Pirithoos, acompanhantes de Teseu, ou o caçador de Calydon. Entre as várias inscrições, notamos que certos objetos são igualmente denominados, não com um nome próprio, mas por seu nome comum. Essa particularidade rara só é encontrada no início da pintura de vasos e gostaria de deter-me nisso para tentar explicá-la, se possível.

A explicação que os próprios homens da Antiguidade deram a este fenômeno foi do tipo racional. Estamos no tempo dito "primitivo", e os pintores não eram capazes de representar corretamente o que eles tinham escolhido mostrar. Era preciso incluir, ao lado da imagem, uma inscrição para explicar a que a imagem se referia. Elien assim descreve:

"No começo da pintura, quando era, por assim dizer, ainda muito rudimentar, representava os seres vivos de modo tão tosco, que os pintores acrescentavam inscrições como: isso é um boi, esse é um cavalo, ou seja: uma árvore." ${ }^{6}$

Segundo Aristóteles:

"Além disso (a definição é errônea), se seu enunciado não permite, a quem a admira, perceber por si próprio se aquela é mesmo

\footnotetext{
2Sobre essas questões, permito-me fazer referência a F. Lissarrague (1985, p.71-93). Ver também Hurwit (1990 p.180-197); Snodgrass (2000, p.22-34); Osborne e Pappas (2007, p.131-155).

3/taca: kalikleas poiase, Jeffery (1961, p.234, pl.45, 2); Ischia: ]inos mepoies[e, Osborne e Pappas (2007, p.136, fig. 5.3).

${ }^{4}$ Athènes, Musée National 1002 (CC657); ABV 4/1, P. de Nettos; Beazley Archive n 300025.

${ }^{5}$ Florence 4209; ABV 76/1; Beazley Archive n³00000.

6:Elien. Histoire Variée, X, 10, trad. A. Reinach. La Peinture Ancienne: textes grecs et latins. Paris: Éditions Macula, 1985.

Nota 7: Aristóteles. Tópicos, VI, 2, 140a, 2O, trad. A. Reinach. La Peinture Ancienne: textes grecs et latins. Paris: Éditions Macula, 1985.
} 
a definição e se ela se parece com as obras dos antigos pintores, cujos temas seriam irreconhecíveis se não tivessem sido indicados por escrito."

Alguns modernos seguiram essa explicação e definem essas inscrições como 'pedagógicas'; ${ }^{8}$ mas os pintores não são professores, e o espectador não está lá para aprender. O melhor é evitarmos projetar nossas categorias e nossas atitudes nessas imagens, que são essencialmente vistas em um banquete e não têm nenhuma didática.

Voltemos ao vaso François, ${ }^{9}$ sobre o qual não se pode dizer que seja obra de um pintor primitivo ou desastrado; aqui encontramos, além dos nomes dos deuses e dos heróis, cinco objetos denominados em três cenas diferentes: bomos, thakos, krene, hydria e lithos.

A menção a uma pedra, lithos, atirada por um centauro em luta com Lápitas, que aparece no pescoço do vaso, reforça a violência dessas criaturas híbridas, armadas não com espadas como os guerreiros, mas com objetos naturais, árvores ou rochas. Essa menção é reforçada pelo uso de nomes 'falantes' dados a alguns centauros desse tipo, como Petraios ou Agrios. Não se trata de explicar o que mostra a imagem, mas de redobrar verbalmente os efeitos que ela explora.

A indicação bomos incisa no altar onde Peleu, em frente a sua casa, recebe Chiron, o bom centauro, faz parte de um conjunto complexo de inscrições, no qual se combinam, além da palavra bomos no altar, a assinatura de Clítias, descendo verticalmente na direção desse mesmo altar, a partir das mãos juntas dos dois protagonistas (figura 1). O termo bomos foca o olhar, como disposto nas inscrições, nesse ponto central, eixo ritual do encontro entre o herói e os deuses, que vieram visitá-lo em um longo cortejo, visto na imagem ao redor de todo o vaso.

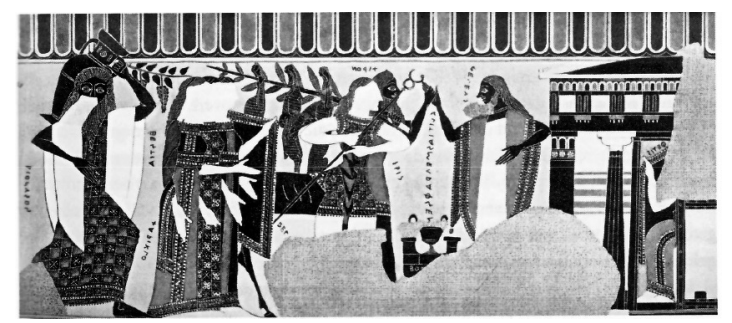

Figura 1: Vaso François

No registro inferior, logo abaixo da residência de Peleu, sob a asa vertical da cratera, aparecem as muralhas de Troia e o velho Príamo, sentado diante de sua cidade. O bloco de pedra, que lhe serve de assento, é denominado por uma inscrição: thakos. Como bem observou N. Strawczynski, trata-se aqui de destacar a ambiguidade entre assento e altar e de encenar o esquema da morte de Príamo, que suplica no altar no momento do Ilioupersis (Strawczynski 1998, p.111-112).

${ }^{7}$ Aristóteles. Tópicos, VI, 2, 140a, 2O, trad. A. Reinach. La Peinture Ancienne: textes grecs et latins. Paris: Éditions Macula, 1985.

8Também Halm-Tisserand (2005, p.50).

${ }^{9}$ Para o próprio vaso, ver a recente obra de Torelli (2007); para as inscrições, o importante estudo de Wachter (1991, p.86-113), e as análises de Strawczynski (1998, p.107-121). 
O assento de Príamo aparece na extremidade direita de um friso, representando Aquiles perseguindo Troilo, que vem à fonte com sua irmã Polixena. Todos esses personagens são denominados, mas também a própria fonte - krene - e hydria novamente para captar o olhar do espectador e marcar a imagem com os termos-chave do que ela expressa. Para compreender de onde ele volta, é preciso se lembrar que a cena é construída em torno de uma fonte, onde a jovem vai encher sua hydria, e que esse lugar tranquilo, domínio de Apolo, aqui presente ao lado da construção, torna-se uma armadilha na qual Aquiles é atingido.

Sobre o vaso François, a escrita se desenvolve sob todas as suas formas, e as palavras inscritas estão, visualmente, a serviço de uma narrativa sugerida pela imagem. Elas aparecem não para capturar o olhar do espectador, mas para orientá-lo e tornar a imagem mais eficaz.

A mesma estratégia gráfica encontra-se nos fragmentos, não atribuídos, de um dinos proveniente da Acrópole. ${ }^{10}$ Vemos uma série de heróis armados, unidos pelos ritos funerários em homenagem a Pélias: na extrema esquerda do fragmento conservado encontram-se Iphitos e um companheiro anônimo, bem perto de um tripé denominado lebes. Esse objeto representa provavelmente o prêmio reservado ao vencedor e se encontra, por essa razão, focalizado por uma inscrição que o valoriza.

\section{Sobre o vaso François, a escrita se desenvolve sob todas as suas formas, e as palauras inscritas estão, visualmente, a serviço de uma narrativa sugerida pela imagem}

Sobre a grande cratera a colunatas, hoje mantida pelo Metropolitan Museum de New York e atribuída a Lydos, ${ }^{11}$ forma-se o cortejo de Dionysos, que guia o retorno de Hefestos ao Olimpo. Ao redor do deus ferreiro, levado por um asno, espalham-se os sátiros: Molpaios toca seu aulos, e Oukalegon se movimenta sob a montaria do deus; esse último é denominado por uma inscrição Hefestos, reforçada por outra, paralela, que se refere ao animal: onos. Esse nome comum não especifica o tipo de montaria (ainda que ele nos esclareça sobre o fato de não se tratar de uma mula), mas sim para evidenciar o papel desse animal, perto dos sátiros por seu itifalismo e por ser tão pouco aristocrático, quando o comparamos com o cavalo. ${ }^{12}$

Na série de ânforas ditas "tirrenas", os pintores fizeram grande uso da escrita. ${ }^{13}$ Alguns inscreveram com precisão vários tipos de nomes e de vocábulos; outros só imitaram seus colegas e com frequência escreveram uma série de letras sem senso linguístico, embora elas conservem um valor dinâmico na imagem, uma vez que elas atraem e orientam o olhar, além de criar um tipo de

\footnotetext{
${ }^{10}$ Athènes Musée National 15147; Graef, Langlotz (1929-1933, I, n 590); Beazley Archive n 1281. ${ }^{11}$ New York, Metropolitan Museum of Art, 1997.388; Beazley Archive n 46026

${ }^{12}$ Sobre a oposição asno-mula, em relação ao cavalo, ver Griffith (2006, p.185-246 e 307-358).

13Sobre os pintores desse grupo, ver Kluiver (1995, p.55-103; 1996, p.1-58; 2003).
} 
"barulho", uma vontade de verbalizar esses signos e de comentar a imagem. A exploração das possibilidades da escrita por esses pintores inclui certas inscrições, relacionadas aos objetos ou aos animais.

O mais notável, pela perspectiva na qual nos atemos aqui, encontra-se em uma ânfora fragmentada da coleção H. Cahn (figura 2). ${ }^{14}$ Vemos uma quadriga, sobre a qual está Amphiaraos, conduzido por Batos. Lembramos que, na expedição dos sete contra Tebas, Amphiaraos, o vidente, tinha previsto o resultado funesto desse combate e não desejava fazer parte dele. Polynice, porém, não pôde persuadir Amphiaraos de partir e usou o juramento que havia feito a sua esposa, Eriphyle, em virtude do qual ele faria o que ela pedisse. Sem poder armar Amphiaraos, Polynice seduz Eriphyle, oferecendo a ela um colar prestigioso que havia sido oferecido nas bodas de Cadmos e Harmonia. Eriphyle aceitou o presente fatal, adorno e panóplia, desempenhando, assim, um papel simétrico e inverso, masculino e feminino. Na ânfora da coleção Cahn, à esquerda da cena, Eriphyle está de pé, assistindo à partida de seu marido. Ela é denominada por uma inscrição disposta horizontalmente sobre a parelha de cavalos, enquanto segura um tipo de coroa com a mão esquerda. Entre ela e o idoso sentado, que se lamenta na frente da biga, lemos a palavra hormos, "colar", designando o objeto que precisamente provocou sua partida.

Para quem não conhece o relato mítico associado a esse episódio, o termo não faz muito sentido; mas, se a história é conhecida, a palavra será suficiente para ativar na memória do espectador o relato que acabamos de relembrar. Dessa forma, a escrita e a imagem produzem os elementos de referência que permitem desenvolver uma narrativa relacionada à representação. Não se trata de tornar compreensível a imagem do colar, mas de lembrar ao espectador o papel central do colar nesse episódio. ${ }^{15}$

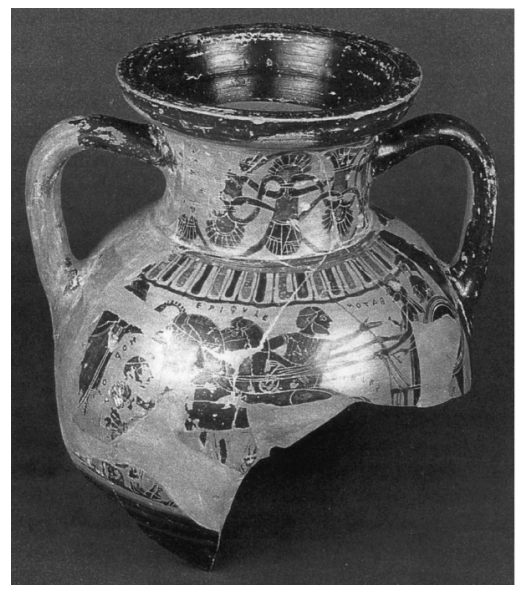

Figura 2: Ânfora fragmentada da coleção H. Cahn.

\footnotetext{
14Bâle, collection H. Cahn, HC 921; Beazley Archive n 7010; Kreuzer (1992).

${ }^{15}$ Em uma cratera coríntia em Berlim (F1655, H. Payne, Necrocorinthia, Oxford, 1931, cat. n¹471), figura a partida de Anfiarau em um carro; à esquerda, a cena é limitada por um pórtico, de onde um grupo de mulheres faz saudações; sobre uma coluna branca, lê-se o nome de Erifila em letras escuras, enquanto um colar grosso se destaca em branco sobre o fundo escuro de seu vestido. O pintor não utiliza uma inscrição para o colar, mas se concentra na composição, sua localização e sua cor.
} 
Outras ânforas tirrenas trazem inscrições ligadas a objetos que nunca são insignificantes. Em uma ânfora em Munique, figura um duelo heroico, que opõe Aquiles a Hector, em torno do cadáver de Troilos. Este último jaz no chão, de costas, já sem suas armas, gymnos. Sua cabeça está escondida por uma estrutura em forma de montículo, decorada por um desenho bicolor em losango, que dá a ele uma aparência de túmulo. À direita, lemos a inscrição bomos, que elimina toda ambiguidade e confirma que Troilos foi abatido por Aquiles perto de um altar, $\mathrm{o}$ que acrescenta à violência do ataque uma dimensão de hybris, de ambição excessiva e orgulho. Aquiles não respeita a proteção que os deuses concedem a quem se refugia perto de seu altar. Para horror adicional, a cabeça de Troilos encontra-se no campo da imagem, na ponta da lança de Aquiles. Considerando a ambiguidade formal do altar-túmulo, o pintor destaca o caráter quase sacrificial da morte de Troilos e usa a palavra bomos para expor a imagem em sua dimensão ritual. Isso permite conectar essa cena a outras, mais explicitamente ligadas ao sacrifício humano, como na ânfora de Londres, na qual Polyxene é degolada no altar. ${ }^{16}$

Em uma ânfora do Louvre (figura 3), ${ }^{17}$ Zeus está sentado e cercado por série de deuses, cujos nomes estão inscritos: Leto, Ares, Afrodite, Dionysos, Ilitia, à esquerda, Poseidon, Amfitrite, Hefesto, à direita. A presença desse último, assim como a de Ilitia, ao lado de Zeus, nos faz pensar no nascimento de Athená, mesmo que a deusa não esteja (ainda) presente na imagem. O deus soberano do Olimpo segura um cetro e um raio, símbolos de sua soberania, à qual adiciona-se o trono, sobre o qual ele se senta sozinho em meio aos olímpicos, que estão de pé. Esse assento está acompanhado da inscrição thronos, que aparece entre os pés do móvel, enfatizando o objeto que o designa, chamando atenção do olhar e colocando o deus em evidência, tal como o repouso de pés, que se encontra na altura dessa inscrição e coloca Zeus acima dos outros deuses.

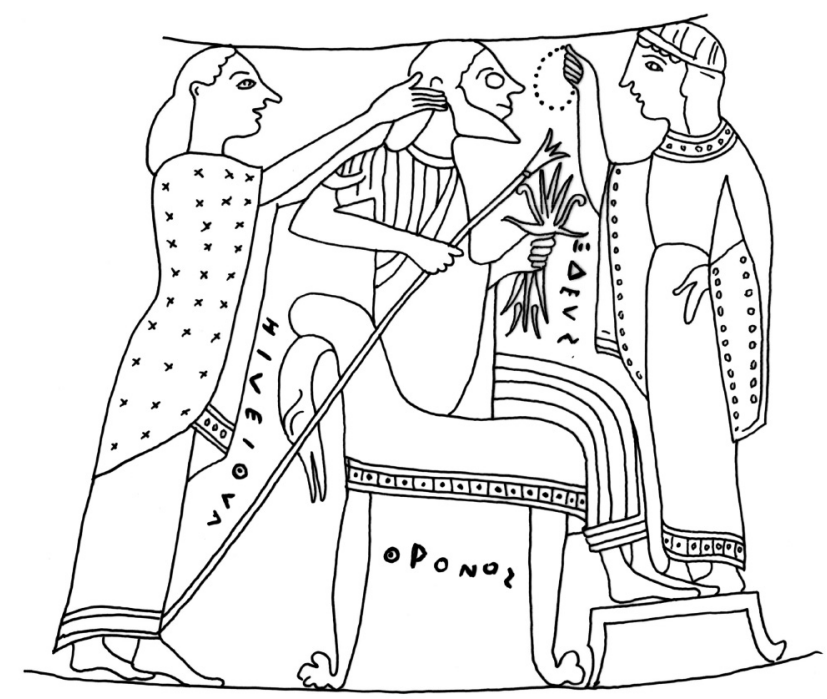

Figura 3: Desenho da ânfora do Louvre.

${ }^{16}$ Londres 1897.7-27.2; ABV 97/27, P. de Timiades; Beazley Archive 310027.

17Louvre E852; ABV 96/13, P. de Prométhée; Beazley Archive 310013. 
Em uma ânfora em Cerveteri, ${ }^{18}$ retrata-se o animal que Héracles captura, designado pela inscrição: elaphos. A imagem é totalmente clara, e o tema, conhecido; trata-se da corça de Cirineia, que Héracles recupera em seu caminho; a inscrição não é de maneira nenhuma necessária, só serve para atrair o olhar e traduzir o episódio em palavras.

\section{A inscrição não é de maneira nenhuma necessária, só serve para atrair o olhar e traduzir o episódio em palauras}

O mesmo procedimento é encontrado em uma kýlix (taça) assinada por Archiklès e Glaukytés. ${ }^{19} \mathrm{~A}$ zona pictórica, muito densa e coberta de personagens, está repleta de inscrições; de um lado, figura a luta de Teseu e Minotauro, em outro, a caça de Calidon. Ao todo, foram denominadas 62 inscrições, minuciosamente analisadas por L. Rebillard (Rebillard 1992, p.501-540). Sobre o lado da caça de Calidon (figura 4), no centro, um enorme javali é cercado pelos caçadores e atacado por três cães; um é Podes, que jaz com a barriga aberta sob o animal, o outro é uma fêmea, Therô, que o morde na coxa, e um terceiro, Leukios, sobe em suas costas. É um cão branco, como seu nome indica. O grupo é aqui detalhado com o auxílio de nomes próprios, assim como os caçadores heroicos, Meleagro e Peleu, Castor e Pólux. O javali, em contrapartida, é simbolizado por uma inscrição que preenche o espaço entre suas costas e o ventre de Leukios: podemos ler Hus, nome genérico de javali. Novamente, a inscrição não acrescenta nada à identificação da besta, mas participa da composição da imagem e se concentra sobre esse ponto central da representação. A mistura dos corpos animais, javali e cães sobrepostos no centro da cena, é enriquecida por uma trama de letras que dá nomes próprios aos cães, assim elevados ao nível dos heróis, e o nome genérico à besta monstruosa, objeto da exploração heroica.

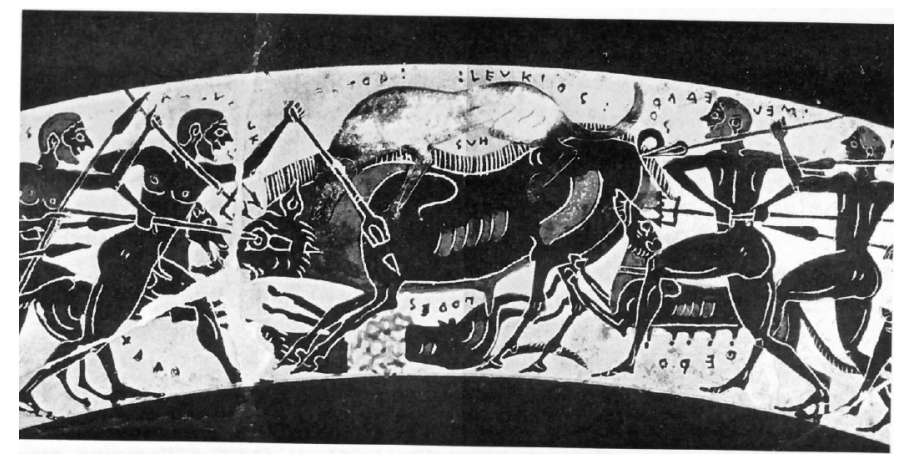

Figura 4: Caça de Calidon.

${ }^{18}$ Cerveteri, sem número; Beazley Archive 7968; Kluiver (1995, p.92, fig.25)

${ }^{19}$ Munich 2243; ABV 163/2; Beazley Archive 310552. 
No outro lado, a luta de Teseu contra o Minotauro é delimitada por uma sequência de figuras imóveis, testemunhas do combate. Atrás de Teseu, encontra-se Athená, e a lira que ela segura é denominada lyra. O instrumento é, assim, valorizado, pois servirá mais tarde para conduzir a dança dos jovens enfim livres e talvez também para contar as proezas do herói atenense. A imagem seria como uma referência à performance poética que transmite os relatos, que se remete a eles mesmos, em um tipo de autorreferência cruzada entre poesia e representação.

Nas alças dessa mesma taça, encontram-se esfinges, cujo papel habitual é sobretudo ornamental; no entanto, os animais se dirigem ao centro da composição e são acompanhados por inscrições concentradas (figura 5): sphix hede chaire.$^{20}$ Essa fórmula é observada em vários títulos. Em outra, na qual o animal é denominado por seu nome genérico, como já vimos, ele é colocado em perigo, por sua inversão entre ornamento e representação. O uso de hede como dêitico (segundo a fórmula citada por Elien) acrescenta um efeito de presença e constrói um quadro expressivo, que envolve o espectador do vaso. Essa dimensão é retomada pelo verbo chaire, que encontramos frequentemente nos vasos de beber, como indicação a quem bebe Beazley (1932, p.167-204). Os efeitos do foco na escrita são, assim, desdobrados e adicionadas à eficácia da imagem.

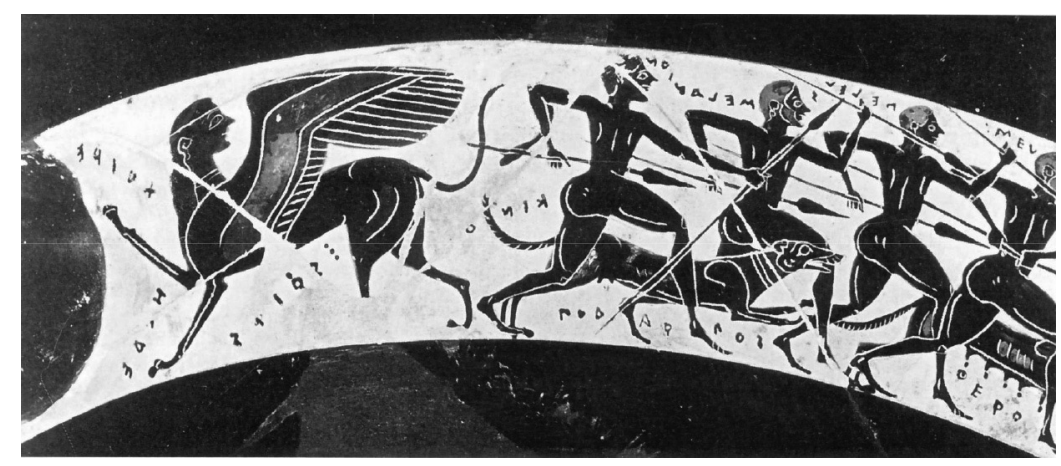

Figura 5: Inscrições na taça.

Outros vasos denominam ainda uma sereia ${ }^{21}$ ou animais notáveis. Esse é particularmente o caso de uma taça assinada por Nearchos, ${ }^{22}$ sobre a qual encontramos as mesmas fórmulas dêiticas, associadas à assinatura (figura 6):

Neandros: epoiesen eu ge pardalis hedi naichi nai me - seiren hodi ge naichi tauros outos seiren.

No verso:

leon ton kapron tondi naichi Neandros: epoiesen eu ge - eu ge naichi nai me [elaph]os hedi

\footnotetext{
20Para o detalhe, ver Rebillard (Op. cit., p.518-520).

${ }^{21}$ Sobre uma hydria do Louvre, E869, grupo de Archippè, lemos, perto de uma sereia, a inscrição siren eimi. 22Boston 61.1073; Paralipomena 69; Beazley Archive 350341; Scheller (1981, p.220-227; H. Immerwahr (1990, p.49, n²29, pl.14, fig.62-65).
} 

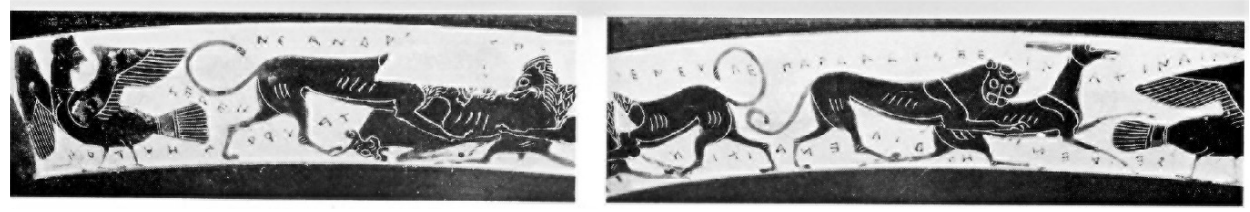

Figura 6: Inscrições na taça assinada por Nearchos

Nenhum relato mítico inclui essa representação. São cenas de lutas de animais, de felinos, leões e panteras, atacando um touro e um cervo sobre o lado principal, um javali (kapron) e um cervo do outro lado, segundo o esquema arcaico que retoma as métaforas homéricas da luta. Nesse sentido, os animais são denominados, como acreditava Elien, não somente porque sem isso seriam irreconhecíveis, mas porque, na prática dos pintores da época (por volta de 540 a.C. para essa taça), denominar uma figura daria a ela um status narrativo, por vezes heroico.

Da mesma forma, em uma ânfora de Würzburg, ${ }^{23}$ Europa é levada por um touro; ela é denominada Europeia, e o touro está acompanhado pela inscrição tauros phorbas de um lado e tauros anaidos de outro. Os dois adjetivos qualificam o touro, no campo, no pasto (phorbas) ${ }^{24}$ ou sem pudor (anaidos), conferindo a ele, de maneira excepcional, as qualidades que só se explicam pelo fato de ser o touro, na verdade, Zeus levando Europa. A metamorfose personaliza o animal, que é assim qualificado de modo específico pelas inscrições, cujo papel é fazer uma ligação com a expressão oral da imagem.

Último exemplo, mais confuso, é uma ânfora atribuída ao grupo tirreno. ${ }^{25} \mathrm{Em}$ seu lado principal (figura 7), mostra um guerreiro correndo, que levanta uma lira em cada mão entre dois enormes galos. O guerreiro denomina-se Moisis, que remete a uma atividade musical; cada lira é acompanhada da inscrição lyra eimi, e os galos têm nomes próprios: Leukos e Chaitos. Beazley comentou essa imagem, Beazley (1927, p.345), indicando que a duplicidade da lira não era significativa, mas simplesmente a marca de um gosto pela simetria; talvez devêssemos ver aqui uma duplicidade expressiva, que insiste na importância da lira. Impõe-se a proximidade com a taça de Archiklès e pela ideia que o pintor integra à imagem, uma referência a uma performance musical. A imagem de um guerreiro músico não é totalmente isolada; Beazley menciona uma pedra gravada em Oxford, ${ }^{26}$ que dispõe de algo semelhante: um guerreiro correndo, galo e lira na mão. Talvez haja algo que nos escape por trás dessa história.

232Würzburg L193; não atribuído; Beazley Archive 44251. Beazley Archive, Universidade de Oxford. Disponível em: www.beazlley.ox.ac.uk.

${ }^{24}$ Sobre o termo phorbas, ver Platon, Lois 666e.

25Liverpool Public Museums 56.19.19; ABV 103/118 próximo a P. de Timiades; Beazley Archive 310117.

${ }^{26}$ Oxford, Ashmolean Museum; Furtwängler (1900, pl.6, 38 et vol. 2, p.28). 


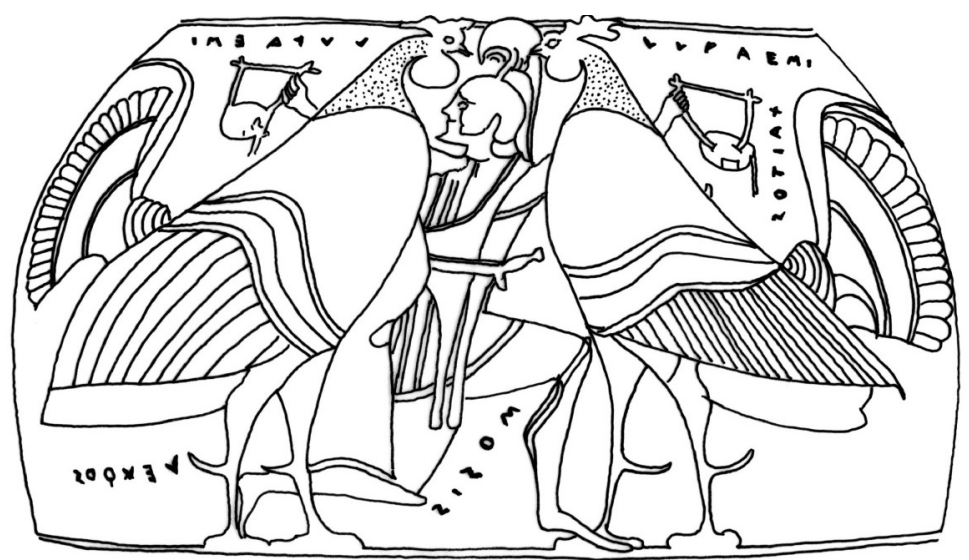

Figura 7: Ânfora atribuída ao grupo tirreno.

Essa última aporia nos permite salientar um fenômeno essencial: as imagens não contam as histórias, mas se referem a elas; reúnem certo número de signos e elementos gráficos que remetem aos episódios, a situações conhecidas pelo espectador. A prova disso é que, se não tivermos em mente as referências necessárias - o que acontece com frequência com os modernos, diante dessas imagens antigas -, não temos condição de dizer a que elas se referem. Entre os signos mobilizados pela imagem, a escrita concede um papel importante à época arcaica, e o uso de nomes para identificar coisas, mesmo se for raro, participa dessa lógica.

Os objetos são denominados por terem um papel sobre o que a imagem se refere. Eles estão lá para que o espectador se expresse, para desencadear um discurso oral, que é produto da memória do espectador. Vemos, conectamos e contamos ou não; nenhuma dessas etapas é obrigatória; as imagens são proposições colocadas sob os olhos do bebedor, que pode ou não, segundo sua competência e vontade, relatar ou fazer um comentário ligado à imagem em questão. $\mathrm{O}$ uso das inscrições pintadas, aplicadas aos objetos, é relativamente rara e não serve para compensar as falhas de imagem ou a incapacidade dos pintores. Faz parte de uma prática mais ampla, que combina imagem e escrita, utilizando os dois modos de 'graphein' de maneira complementar. Esse uso da escrita não é a marca de um triunfo da literacy; notamos diversos graus de visibilidade das inscrições e competência escritural da parte dos pintores. Mesmo representando a marca de um avanço da literacy, essas inscrições são um prenúncio da oralidade; elas chamam atenção, atraem o olhar e focam nos elementos da imagem, cujo papel é assim valorizado. Com isso, elas incitam o espectador a levar em conta os objetos ou os animais, assim denominados para dar lugar à performance oral, que reacenderá a memória desses relatos, independentemente do que eles sejam. Essa prática dura pouco tempo, entre 580 e 540 a. C., e, com a mudança para as figuras vermelhas, esse tipo de inscrições desaparece no momento em que se generaliza cada vez mais a cultura da escrita. 


\section{Apêndice: nomes comuns inscritos na cerâmica ática ${ }^{27}$}

\section{Objetos}

Bomos:

Munich 1426; $A B V$ 95/5, Tyrrhenian Group; Barch 310005.

Bale, Cahn HC 805; Group E; Barch 6902.

Florence 4209; ABV76/1, Kleitias; Barch 300000.

Krene:

Florence 4209; $A B V 76 / 1$, Kleitias; Barch 300000.

Londres B 331; ABV 261/41; man. de P. de Lysippidès; Barch 302273 (Callirhoe krene).

Rome, Torlonia; $A R V^{2}$ 30/2, Hypsis; Barch 200171 (Dionysia krene).

Lebes:

Athènes MN 15147 (Acróp. 1.590); não atribuído; Barch 1281.

Lithos:

Florence 4209; ABV 76/1, Kleitias; Barch 300000.

Lyra:

Munich 2243; $A B V$ 163/2, Archikles e Glaukytes; Barch 310552.

Liverpool 59.19.19; ABV 103/118, Tyrrhenian Group; Barch 310117 (Lyra eimi).

Hormos:

Bale, Cahn HC 921; Archippe Group; Barch 7010.

Thakos:

Florence 4209; ABV76/1, Kleitias; Barch 300000.

Thronos:

Louvre E 852; $A B V$ 96/13 Tyrrhenian Group; Barch 310013.

Hydria:

Florence 4209; $A B V$ 76/1, Kleitias; Barch 300000.

\section{Animais}

\section{Glauxs:}

Berlin F 1698; ABV 136/54, Group E; Barch 310314.

Elaphos:

Cerveteri ss. n; Para 40, Tyrrhenian Group; Barch 7968.

Boston 61.1073; Para 69/3, oleiro Neandro; Barch 350341; ([elaph]os).

\section{Kapron:}

Boston 61.1073; Para 69/3, oleiro Neandro; Barch 350341.

Leon:

Boston 61.1073; Para 69/3, oleiro Neandro; Barch 350341.

Athènes, Acrópole I, 1632; Barch 15673 (lheon).

Onos:

New York 1997.388; Lydos; Barch 46026.

Pardalis:

Boston 61.1073; Para 69/3, oleiro Neandro; Barch 350341.

27Só abordo aqui as inscrições áticas. Para exemplos corintianos, ver Wachter (2001); (Askalabos: Cor 87; Hippoi: Cor 71; Kapros: Cor 102; Ketos: Cor 101; Onos: Cor 101). 
Siren:

Louvre E 869; $A B V$ 106/2, Tyrrhenian group; Barch 310146 (Siren eimi). Boston 61.1073; Para 69/3, oleiro Neandro; Barch 350341 (Seren).

Sphix:

Munich 2243; $A B V$ 163/2, Archikles e Glaukytes; Barch 310552.

Tauros:

Boston 61.1073; Para 69/3, oleiro Neandro; Barch 350341.

Würzburg L 193; não atribuído; Barch 44251 (tauros phorbas; tauros anaides). Hus:

Munich 2243; $A B V$ 163/2, Archikles e Glaukytes; Barch 310552.

\section{Referências bibliográficas}

BEAZLEY, J. Little Master cups, JHS. 52, 1932.

BEAZLEY, J. Some inscriptions on vases, AJA. 31, 1927.

FURTWÄNGLER, A. Antike gemmen. Berlim, 1900.

GRAEF, B e Langlotz, E. Die antiken vasen von der Akropolis zu Ahen. Berlim, 1929-1933, I, n 590. GRIFFITH, M. Horsepower and donkeywork: equids and the ancient Greek imagination, Classical Philology. 101, p. 185-246, 2006.

HALM-TISSERAND M. Nommer les dieux au flanc des vases. In: BELAYCHE, N. et al. Nommer les dieux. Théonymes, épithètes, épiclèses dans l'Antiquité. Turnhout Rennes, 2005.

HURWIT, J. The words in the image: orality, literacy, and early Greek art, Word \& image, 6, 1990. IMMERWAHR, H. Attic script, a survey. Oxford, 1990.

JEFFERY, L. The local scripts of archaic Greece. Oxford, 1961.

KLUIVER, J. Early Tyrrhenian: Prometheus Painter, Timiades Painter, Goltyr Painter, BaBesch 70, 1995.

KLUIVER, J. The Five Later Tyrrhenian Painters, BaBesch. 71, 1996.

KLUIVER, J. The Tyrrhenian group ofblack-figure vases from the Athenian kerameikos to the tombs of South Etruria. Amsterdam: Dutch Archaeological and Historical Society, 2003.

KREUZER, B. Frühe zeichner. Freiburg, 28, 1992.

LISSARRAGUE, F. Paroles d'images: remarques sur le fonctionnement de l'écriture dans l'imagerie attique. In: CHRISTIN, A. M. (ed.). Ecritures II. Paris, 1985. p. 71-93.

OSBORNE R. e PAPPAS, A. Writing on archaic Greek pottery. In: NEWBY, Z. e LEADER-NEWBY, R. (eds.). Art and inscriptions in the ancient world. Cambridge, 2007. p.131-155.

REBILLARD, L. La coupe d'Archiklès et de Glaukytès: l'écrit dans l'image, $B C H$ 116, 1992.

SCHELLER, M. Die bandschale des neandros, Museum helveticum, 38, 1981.

SNODGRASS, A. The uses of writing on early Greek, painted pottery. In: RUTTER, K. e SPARKES, B. (eds.). Word and image in ancient Greece. Edinburgh, 2000. p.22-34.

STRAWCZYNSKI, N. L'inscription comme élément de composition, Mètis 13, 1998.

TORELLI, M. Le strategie di Kleitias. Milan, 2007.

WACHTER, R. Non-Attic greek vase inscriptions. Oxford, 2001.

WACHTER, R. The inscriptions on the François Vase, Museum Helveticum, 48, 1991. 